\title{
ANNEALING EFFECTS OF SEMICONDUCTING BARIUM-TITANATE THERMISTER
}

\section{Yeong-Chin Chen}

Department of Computer Science and Information Engineering, Diwan College of Management, No. 87-1, Nanshi Li, Madou Town, Tainan County, Taiwan 72153, R.O.C., ycchenster@gmail.com

Follow this and additional works at: https://jmstt.ntou.edu.tw/journal

Part of the Electrical and Computer Engineering Commons

\section{Recommended Citation}

Chen, Yeong-Chin (2007) "ANNEALING EFFECTS OF SEMICONDUCTING BARIUM-TITANATE THERMISTER," Journal of Marine Science and Technology. Vol. 15: Iss. 4, Article 5.

DOI: $10.51400 / 2709-6998.2047$

Available at: https://jmstt.ntou.edu.tw/journal/vol15/iss4/5

This Research Article is brought to you for free and open access by Journal of Marine Science and Technology. It has been accepted for inclusion in Journal of Marine Science and Technology by an authorized editor of Journal of Marine Science and Technology. 


\section{ANNEALING EFFECTS OF SEMICONDUCTING BARIUM-TITANATE THERMISTER}

\section{Acknowledgements}

The authors would like to thank the National Science Council of the Republic of China, Taiwan for financially supporting this research under Contract No. NSC95-2221-E-272-005. 


\title{
ANNEALING EFFECTS OF SEMICONDUCTING BARIUM-TITANATE THERMISTER
}

\author{
Yeong-Chin Chen*
}

Key words: annealing, grain boundary, semiconductor, Barium-Titanate, PTCR.

\begin{abstract}
Two Positive Temperature Coefficient of Resistivity (PTCR) ceramics with composition $\mathrm{A},\left(\mathrm{Ba}_{0.997} \mathrm{Sb}_{0.003}\right) \mathrm{Ti}_{1.005} \mathrm{O}_{3}$, and composition $\mathrm{B},\left(\mathrm{Ba}_{0.997} \mathrm{Sb}_{0.003}\right) \mathrm{Ti}_{1.005} \mathrm{O}_{3}+0.1 \mathrm{~mole} \% \mathrm{MnO}_{2}$ were fabricated and examined herein. The ceramic grain size, oxygen pressure and annealing time need to be simultaneously controlled to obtain an optimum PTCR resistor. Additionally, the stoichiometric proportions of the constituent elements must be weighted carefully in order to produce good quality PTCR devices. This study thoroughly explores all the factors affecting the PTCR characteristics.

Experiments were developed to verify that PTCR phenomena are strongly influenced by oxygen absorption. As the samples were annealed in Air atmosphere, the numbers of foreign ions compensation were increased by this oxidation process. The Schottky barrier is formed between grains and grain boundaries, improving the PTCR effect and resulting in very steep gradient Resistivity-Temperature (R-T) plots. Annealing samples in oxygen atmosphere also improves the PTCR effect and reduces the annealing time dramatically, but increases the room-temperature resistivity. By contrast, annealing in reduced air $\left(98 \% \mathrm{~N}_{2}+2 \% \mathrm{H}_{2}\right)$ atmosphere decreases the resistivity of the ceramics, and also diminishes the PTCR effect of the ceramics.

The complex-plane-impedance method was used to analyze the influence of annealing condition (temperature, time and atmosphere) on the PTCR devices. Our study inferred that PTCR mechanism originated from the grain boundaries rather than the bulk. Annealing at $1200^{\circ} \mathrm{C}$ was found to control the PTCR characteristics of the ceramics more effectively than the traditional cooling rate control process. The annealing processing technology and theoretical mechanism affecting the PTCR ceramics were designed and discussed in detail. Factors influencing the PTCR phenomena were studied, showing that the design of the PTCR devices is practical.
\end{abstract}

\section{INTRODUCTION}

Oxidized barium titanate $\left(\mathrm{BaTiO}_{3}\right)$ is an insulator. $\mathrm{N}$-type semiconducting $\mathrm{BaTiO}_{3}$ can be formed in two

Paper Submitted 03/21/06, Accepted 12/21/06. Author for Correspondence: Yeong-Chin Chen. E-mail: ycchenster@gmail.com

*Department of Computer Science and Information Engineering, Diwan College of Management, No. 87-1, Nanshi Li, Madou Town, Tainan County, Taiwan 72153, R.O.C. ways, by doping with donors, or treating it in a reduced oxygen atmosphere. High-temperature in reduced oxygen $\left(98 \% \mathrm{~N}_{2}+2 \% \mathrm{H}_{2}\right)$ atmosphere produces a semiconducting material with room temperature resistivity as low as $1 \Omega-\mathrm{cm}$. The conduction in these oxygen deficient ceramics with the formula $\mathrm{BaTiO}_{3-\mathrm{x}}$ probably arises from the two electrons which are necessarily left behind to ensure that each oxygen vacancy maintains a charge balance [3]. Substitution of 0.15-0.3 at\% (atomic percentage) of donor ions of higher valency than barium or titanium ions leads to semiconductive behavior even after sintering in air for a long time, with a resistivity of $10 \Omega-\mathrm{cm}$ or above. The conductivity apparently results from the electron exchange between $\mathrm{Ti}^{+4}$ and $\mathrm{Ti}^{+3}[15]$.

The resistivity of semiconducting barium titanate formed either by annealing in oxygen deficient atmosphere or donors doping methods can be increased by annealing in an oxidizing atmosphere. However, only the doped semiconducting barium titanate fired in an oxidizing atmosphere [12] demonstrates the so-called PTCR effect, which is an abrupt increase in resistivity above the Curie point. The PTCR effect is believed to be related to oxygen absorption [16] and subsequent trapping of conduction electrons at the grain boundaries. However, Daniel et al. [8] have proposed that the acceptors at the grain boundary layer consist of Ba vacancies forming a three-dimensional zone extending inside the grains.

The purpose of this research is to investigate the annealing effect on the PTCR characteristics of Sbdoped $\mathrm{BaTiO}_{3}$ ceramics by annealing them in different gas atmospheres [1] with and without addition of $\mathrm{MnO}_{2}$. The experiments also confirm that the PTCR effect is a grain boundary rather than a bulk phenomenon, while oxygen can significantly influence this resistivity anomaly. By annealing the sample at a specific temperature for a period of time can control the PTCR characteristics more precisely than annealing the samples during the cooling process (ramp down the temperature to room temperature at a specific cooling rate), and this can offer a quantitative reference for designing the PTCR ceramics. 


\section{EXPERIMENTAL PROCEDURES}

Merck Industrial grade $\mathrm{BaCO}_{3}$, and $\mathrm{TiO}_{2}$ powders were first weighed in accordance with the basic composition of $\mathrm{BaTi}_{1.005} \mathrm{O}_{3}$. The weighed powders were mixed by wet-milling with agate balls in rubber ball mills for about 2 hours. Distilled water was utilized in the milling, and the mixtures were then dried and pulverized. To ensure complete formation of perovskite $\mathrm{BaTi}_{1.005} \mathrm{O}_{3}$ ceramics, the pulverized mixtures were calcined at $1100^{\circ} \mathrm{C}$ for 2 hours.

The calcined powder was ball-milled, dried and ground again with the composition $\mathrm{BaTi}_{1.005} \mathrm{O}_{3}+x$ mole $\% \mathrm{Sb}_{2} \mathrm{O}_{3}$, with $0.025<x<0.25$. The powder was then pressed into disk-shape samples $(15 \mathrm{~mm}$ in diameter by $2 \mathrm{~mm}$ thick) under a pressure of $350 \mathrm{~kg} / \mathrm{cm}^{2}$, using distilled water pluses 50\% PVA as binder. The disc-shape samples were sintered at $1350^{\circ} \mathrm{C}$ for 30 minutes and then cooled down to room temperature at a rate of $-10^{\circ} \mathrm{C} / \mathrm{min}$. After the sintering process, a specific percentage of $\mathrm{Sb}_{2} \mathrm{O}_{3}$ was selected to form the semiconducting ceramic specimens with the composition $\left(\mathrm{Ba}_{1-\mathrm{x}} \mathrm{Sb}_{\mathrm{x}}\right) \mathrm{Ti}_{1.005} \mathrm{O}_{3}$.

The semiconducting samples were then annealed at $1200^{\circ} \mathrm{C}$ for various periods of time ranging from 0 to 28 hours. Various gases (air, reduced air and oxygen) were introduced into the furnace during annealing. The semiconducting ceramics were formed and densified by sintering.

Once the specific mole percentage of $\mathrm{Sb}_{2} \mathrm{O}_{3}$ to form semiconducting ceramic specimens with the minimum resistivity at room temperature was found, an additional dopant $\mathrm{MnO}_{2}$ was then added to form the material with composition $\mathrm{BaTi}_{1.005} \mathrm{O}_{3}+x$ mole $\% \mathrm{Sb}_{2} \mathrm{O}_{3}+$ $y$ mole $\% \mathrm{MnO}_{2}$ to enhance the PTCR phenomena. The final mixture was then undergone further sintering and annealing procedure. Most of the $\mathrm{MnO}_{2}$ was presumed to be segregated at the grain boundary of $\left(\mathrm{Ba}_{1-\mathrm{x}} \mathrm{Sb}_{\mathrm{x}}\right)$ $\mathrm{Ti}_{1.005} \mathrm{O}_{3}$ but some $\mathrm{MnO}_{2}$ could still go into the grains. The characteristics of ceramic specimens with compositions $\mathrm{BaTi}_{1.005} \mathrm{O}_{3}+x$ mole $\% \mathrm{Sb}_{2} \mathrm{O}_{3}$ (composition $\mathrm{A}$ ) and $\mathrm{BaTi}_{1.005} \mathrm{O}_{3}+x$ mole $\% \mathrm{Sb}_{2} \mathrm{O}_{3}+y$ mole $\% \mathrm{MnO}_{2}$ (composition $\mathrm{B}$ ) were measured and compared after annealing in different conditions.

After the sintered ceramic pellets were polished, a metalization paste (Dupant 4102) was brushed on both surfaces of the pellets to provide ohmic contacts. The specimens were kept at room temperature for more than 24 hours for stabilization after the metalizations were fired. The Resistivity-Temperature and Dielectric-Temperature characteristics of the samples were measured from room temperature to $300^{\circ} \mathrm{C}$ with a temperature rise rate of $5^{\circ} \mathrm{C} / \mathrm{min}$, using a two-probe method with dc bias applied in the ohmic regions. Two point probe method is utilized to measure the resistance of the PTCR device. The resistivity of the device can be obtained by referring to the equation $R=\rho \frac{\ell}{A}$, where $\mathrm{R}$ is the resistance, $\rho$ is the resistivity, $A$ is the area, $\ell$ is the length.

\section{RELATED THEORIES OF PTCR PHENOMENA}

\section{Heywang model}

The PTCR phenomena can be described by the original grain boundary barrier model of Heywang [10] as extended in subsequent studies. In this model as illustrated in Figure 1, we assumed that oxygen ions are absorbed on the grain boundaries at a concentration of $N_{s}$ per $\mathrm{m}^{2}$, attracting electrons from the surface layers of the crystals with a concentration of $n_{s}$ per $\mathrm{m}^{2}$ and creating a surface charge density of $Q=-2 q N_{s}=-q n_{s}$ $\mathrm{m}^{-2}$ and two space-charge layers with a thickness $b=$ $N_{s} / n_{1}$, where $n_{1}$ denotes the bulk electron concentration. Consequently, the maximum electric potential at the grain boundary is derived as [10]

$$
\psi_{0}=-\frac{K T}{q}\left(\frac{b}{L_{D}}\right)^{2}=-\frac{Q^{2}(T-\theta)}{8 \varepsilon_{0} n_{1} q C}=-\frac{q n_{s}^{2}}{8 \varepsilon_{0} \varepsilon_{r} n_{1}},
$$

where $q$ is the positive elementary charge, $\varepsilon_{r}=\left(\frac{C}{T-\theta}\right)$ the relative dielectric permittivity, $\theta$ the Curie point, $C=1.2 \times 10^{5}$ is the dimensionless Curie constant and $L_{D}$ denotes the Debye length, given by

$$
L_{D}=\left(\frac{2 \varepsilon_{0} \varepsilon_{r} K T}{n_{1} q^{2}}\right)
$$

Heywang revealed that the barrier is governed by the available amount of surface traps $N_{s}=-Q / 2 q$, and $\psi_{0}$

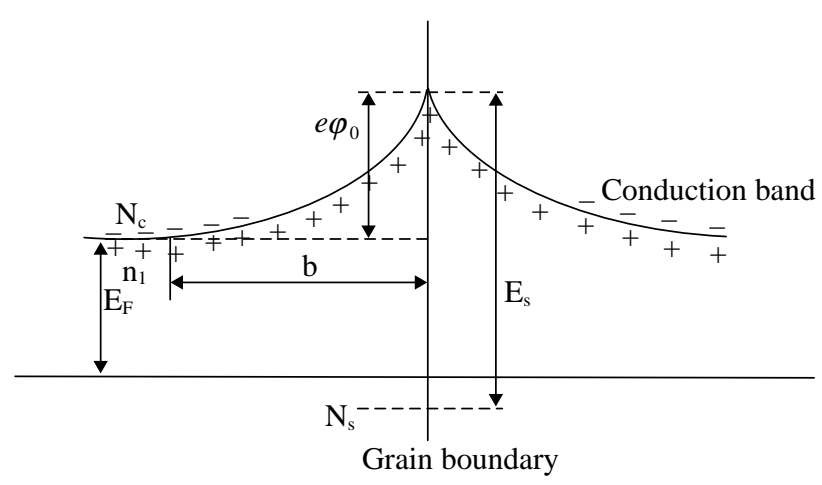

Fig. 1. Heywang model of a grain boundary barrier. 
also increases in proportion to $T-\theta$. This phenomenon reveals that the resistivity increases due to the increase of the temperature. As the temperature increases above the Curie temperature [17], the energy states (traps) of the absorbed oxygen atoms $N_{s}$ rise together with the surface potential until they meet the Fermi level $E_{F}$ of the semiconductor, and gradually acquire a reduced electron concentration $\left(n_{s}\right)$, so that the electric potential begins to decrease slowly and showing the low resistivity characteristic.

Significantly, ferroelectric materials have nonlinear dielectric characteristics. Therefore, Daniels and Wernicke [9] modified the Heywang model and reported that the Poisson equation needs to be utilized and can be expressed as

$$
\frac{d\left(\varepsilon_{0} E+P_{s}\right)}{d x}=\rho,
$$

where $\rho$ is the volume charge density, $\varepsilon_{0}$ is the dielectric permittivity in vacuum, $E$ is the electric field intensity, $P_{S}$ is the electrical polarization.

Subsequently, the maximum electric potential at the grain boundary is modified to be [9]

$$
\psi_{0}=\frac{q\left(N_{s}-2 P_{s}\right)^{2}}{8 \varepsilon_{0} \varepsilon_{r} n_{1}} .
$$

Since $P_{s}>$ zero, the maximum electric potential will be lower for ferroelectric materials. Eq. (4) implies the resistivity will also be lowered at room temperature.

\section{Defect chemistry}

When the donor-doped Bariun-Titanate ceramic specimens are fired in a high temperature environment, considering only an oxygen partial pressure equivalent to that of air, the simplified conditions of electroneutrality obtained from these calculations can be coordinated with the following scheme [7]:

$\mathrm{T}>1500^{\circ} \mathrm{C}$;

$N_{D}=\mathrm{N}$; electron compensation

$1220^{\circ} \mathrm{C}<\mathrm{T}<1500^{\circ} \mathrm{C}$;

$N_{D}=2\left[\mathrm{VB}_{\mathrm{a}}\right]+\mathrm{n}$; mixed compensation

$\mathrm{T}<1220^{\circ} \mathrm{C}$;

$N_{D}=2\left[\mathrm{VB}_{\mathrm{a}}\right] ;$ vacancy compensation

This scheme reveals that vacancy compensation takes place preferentially with decreasing temperature in donor-doped $\mathrm{BaTiO}_{3}$. In our study, the specimens were sintered in air at $1350^{\circ} \mathrm{C}$ in an atmosphere that the oxygen partial pressure is in equilibrium with that of air, and then the temperature was hen ramp ramped down to the annealing temperature of $1200^{\circ} \mathrm{C}$ at a rate of $-10^{\circ} \mathrm{C} /$ min. According to Eq. (5-2), a homogeneous, mixed compensation happens within the material in the cooling process. Since the specimen is cooled at the normal furnace rate, the equilibrium restoration [7] initially follows the temperature decrease. However, as the temperature continues to drop, the equilibrium restoration stops, meaning that the atomic defects are frozen into the grain of the specimen. If the specimens are annealed at $1200^{\circ} \mathrm{C}$, the regions close to the grain boundary [4] will remain in equilibrium, while the defect concentration in the bulk of the grain is unable to change. This heterogeneous defect distribution implies that, according to Eq. (5), a thin layer at the grain boundary has already achieved complete Ba vacancy compensation (Eq. 5-3), while the mixed compensation (Eq. 5-2) is maintained within the bulk of the grain. It means that there is a potential barrier built-up in the grain boundary because of the annealing process at $1200^{\circ} \mathrm{C}$, but the bulk of the grain remains semiconductive.

\section{RESULTS AND DISCUSSIONS}

\section{Effect of annealing on the temperature dependency of resistance}

In Figure 2, the DC resistivity values of the composition $\mathrm{A}, \mathrm{BaTi}_{1.005} \mathrm{O}_{3}+x$ mole $\% \mathrm{Sb}_{2} \mathrm{O}_{3}$, are expressed as a function of $\mathrm{Sb}_{2} \mathrm{O}_{3}[6,14]$. The specimens were sintered at $1350^{\circ} \mathrm{C}$ in air for 30 minutes and ramped down to room temperature at a cooling rate of $-10^{\circ} \mathrm{C} /$ min without annealing at $1200^{\circ} \mathrm{C}$. The experimental results show that pure $\mathrm{BaTiO}_{3}$ ceramic is an insulator, and that by increasing the concentration of $\mathrm{Sb}_{2} \mathrm{O}_{3}$ will

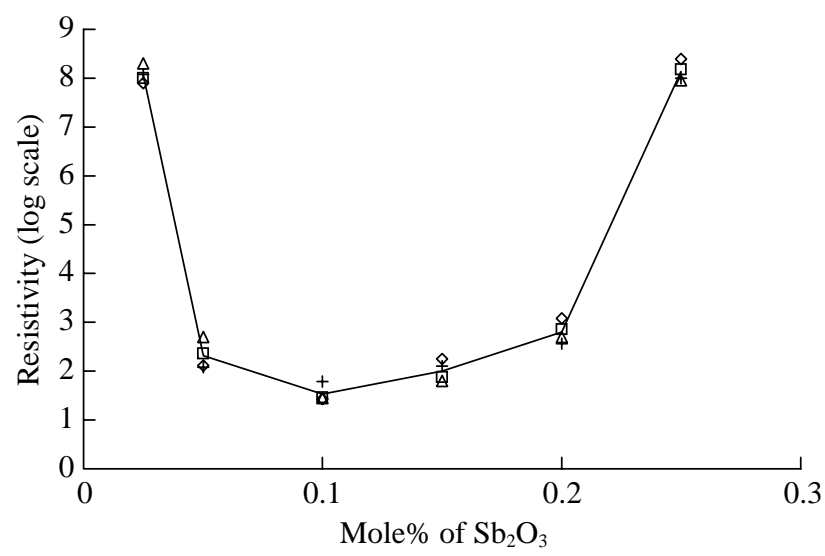

Fig. 2. Resistivity of Bariun-Titanate versus $\mathrm{Sb}_{2} \mathrm{O}_{3}$ additives. 
initially lower the resistivity to a minimum at approximately 0.1 mole\% of $\mathrm{Sb}_{2} \mathrm{O}_{3}$ (or equivalently 0.2 mole\% of $\mathrm{Sb}$ ). The resistivity will then increase rapidly with further addition of $\mathrm{Sb}_{2} \mathrm{O}_{3}$. This phenomenon has two possible explanations. One explanation is that if the $\mathrm{Sb}$ concentration exceeds that of $\mathrm{TiO}_{2}$, then the extra $\mathrm{Sb}$ might occupy Ti sites and lead to an increase in resistivity, or alternatively, the rapid increase in resistivity might be due to formation of too many Ba vacancies by incorporating more $\mathrm{Sb}$ molecules.

Figure 3 depicts the dependence of the R-T characteristics on varying annealing time at $1200^{\circ} \mathrm{C}$. Figure 4 reveals that maximum resistivity $\left(\mathrm{R}_{\max }\right)$ initially increases rapidly but then slows down for further annealing; while the minimum resistivity $\left(R_{\min }\right)$ shows
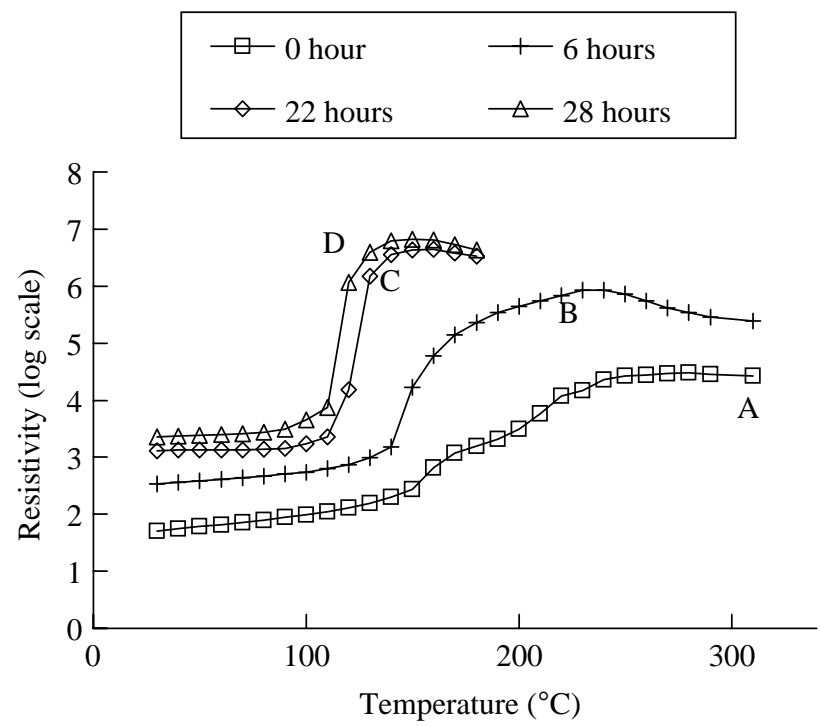

Fig. 3. The resistivity profile of composition A for various annealing time in air.

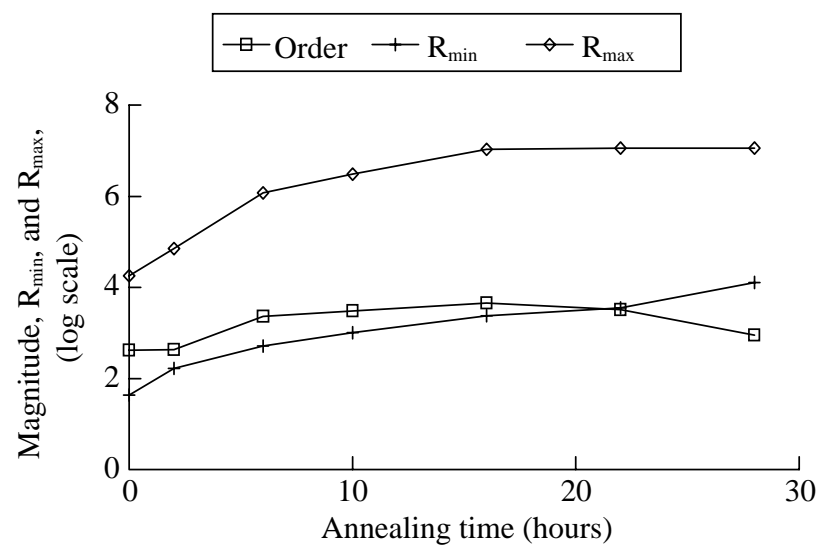

Fig. 4. The PTCR Characteristic of composition A for various annealing time. a linear increase with the annealing time. Maximum resistivity can be achieved by annealing for around 16 hours at $1200^{\circ} \mathrm{C}$. The value will then decrease for annealing time longer than 16 hours. For the nonannealing case (curve A in Figure 3), the cooling rate $\left(-10^{\circ} \mathrm{C}\right)$ was so high that vacancy compensation $(\mathrm{Ba}$ vacancies) did not have sufficient time to maintain equilibrium with oxygen and diffuse into the grains, meaning that the potential barrier could not be established. The rapid cooling resulted in a non-equilibrium and a low activation energy, leading to a low resistivity and unobvious PTCR effect, demonstrating that the critical point for the non-equilibrium compensation (electron compensation > barium compensation) is around $1200^{\circ} \mathrm{C}$. If samples were held at that critical temperature for a period of time, then further mixed compensation could occur, which would be the best way to control the barrier potential of the PTCR ceramics.

Figure 5 shows the magnitude $\left(\log \left(\mathrm{R}_{\max } / \mathrm{R}_{\min }\right)\right)$ and slope $\left(\log \left(\left(\mathrm{R}_{\max }-\mathrm{R}_{\mathrm{tc}}\right) /\left(\mathrm{R}_{\mathrm{tc}}\left(\mathrm{T}_{\max }-\mathrm{T}_{\mathrm{c}}\right)\right)\right)\right)$ of PTCR as a function of the added $\mathrm{MnO}_{2}$ [5]. Under the same annealing condition, the effects of PTCR were improved by the addition of $\mathrm{MnO}_{2}$. When the added concentration of $\mathrm{MnO}_{2}$ was above 0.12 moles\%, the PTCR effect diminished, and the sample behaved as an insulator.

Figure 6 displays the dependence of the R-T characteristics of composition $\mathrm{B}$ on varying the annealing time at $1200^{\circ} \mathrm{C}$, respectively. A comparison of Figure 6 with Figure 3 shows that an additional doping with acceptors decreases the charge carrier density $n_{1}$ of the bulk and a change in the overall density of the grainsurface acceptor states, (sum of intrinsic cation vacancy enrichment and adsorbed oxygen and extrinsic acceptors) and additionally shifts the centers of acceptor energy levels [11] at the grain boundary, in those cases where the doped acceptors start to dominate the PTCR-active grain surface acceptor states with increasing concen-

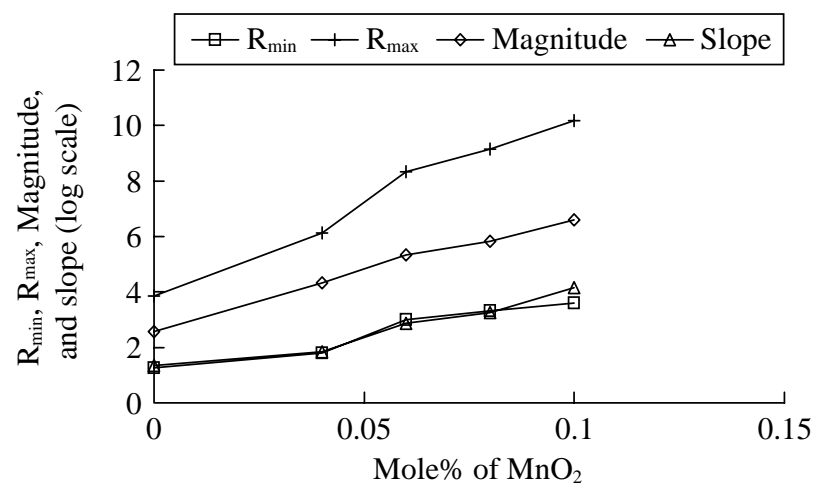

Fig. 5. The PTCR Characteristic of composition B for various $\mathrm{MnO}_{2}$ additives. 


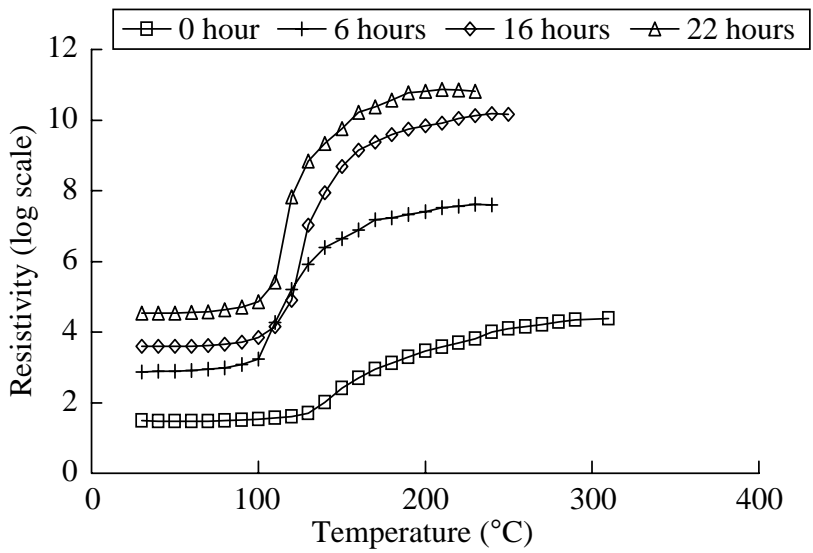

Fig. 6. The Resistivity profile of composition $B$ for various annealing time.

tration. Hence, Mn could increase the room temperature resistivity and enhance the magnitude and steepness of PTCR.

Figure 7 illustrates the dependence of the PTCR characteristics of composition $\mathrm{B}$ on varying the annealing time at $1200^{\circ} \mathrm{C}$. When comparing Figures 7 and 4 , the magnitude of PTCR $\left(\log \left(\mathrm{R}_{\max } / \mathrm{R}_{\min }\right)\right)$ demonstrate that adding 0.1 mole $\mathrm{Mn}^{+4}$ could enhance the magnitude of PTCR from 3.5 to 6.5 for 16 hours annealing in air. $\mathrm{Mn}^{+4}$ was found to form a deep level [11] and increase the surface state, in turn increasing the potential barrier of the grain boundary and the PTCR magnitude. Since both compositions $\mathrm{A}$ and $\mathrm{B}$ exhibited the highest magnitude of PTCR for annealing at $1200^{\circ} \mathrm{C}$ for 16 hours, it proves that the annealing process can precisely control the thickness of Ba vacancy compensation layer very well than the traditional process of cooling rate control.

\section{Annealing in different gas atmospheres}

The R-T characteristics of the specimens with composition $\mathrm{B}$ annealed at $1200^{\circ} \mathrm{C}$ in different gas atmospheres are illustrated in Figure 8, showing that samples annealed in atmosphere of high oxygen content have the following results:

1. An increase in the steepness of the R-T plot in the transition temperature range from low to high.

2. An increase in the magnitude of PTCR .

3. An increase in the room temperature resistivity.

While the samples were annealed in reduced air $\left(98 \% \mathrm{~N}_{2}+2 \% \mathrm{H}_{2}\right)$ [2], anion vacancies (oxygen vacancies) were generated and electron compensation would occur to maintain the electrical neutrality, increasing the conductivity of the ceramics. Heywang considered that no oxygen was absorbed in the grain boundaries to form a depletion layer, and therefore that

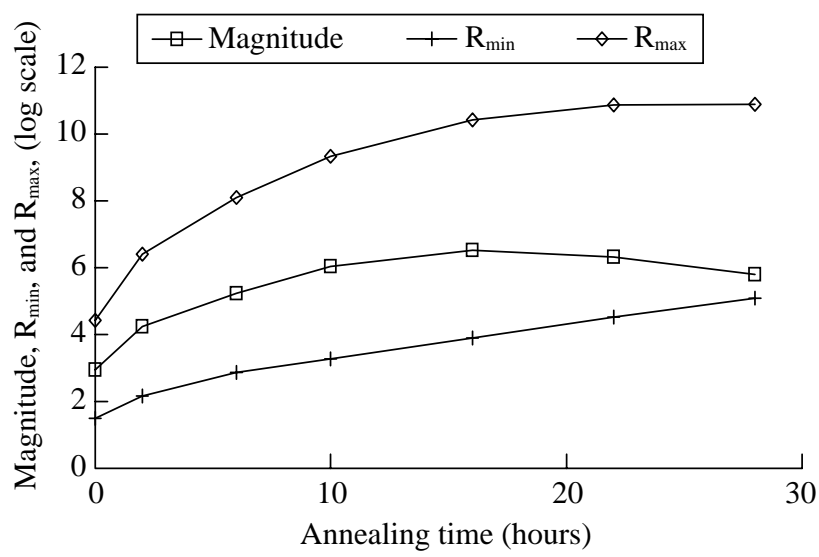

Fig. 7. The PTCR Characteristic of composition B for various annealing time.

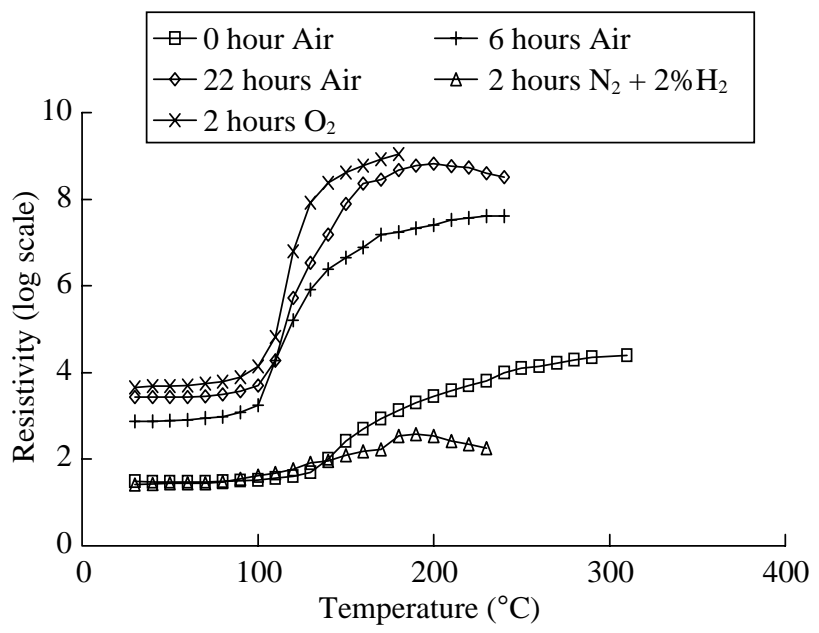

Fig. 8. The PTCR characteristics of composition B (0.1\% Mn doped) annealed in various atmosphere.

vacancy compensation (Ba compensation) was suppressed and the potential barrier was not built, the ceramic exhibited a poor PTCR effect. As the oxygen pressure increases, foreign ions are increasingly compensated by the oxidation process (formation of barium vacancies), and this Schottky barrier was formed between grains and grain boundaries to benefit the PTCR effect producing steep R-T plots.

As shown in Figure 9, the samples of composition $B$ were first treated in air to obtain a high magnitude of PTCR, shown as curve A. Subsequently, the electrodes were removed from the samples and were re-annealed in a reduced atmosphere for 2 hours, thus the $\mathrm{R}-\mathrm{T}$ plots were obtained as curve B. The samples' electrodes were again removed and re-oxidized in an oxygen atmosphere for 2 hours. The results of R-T plots are shown 


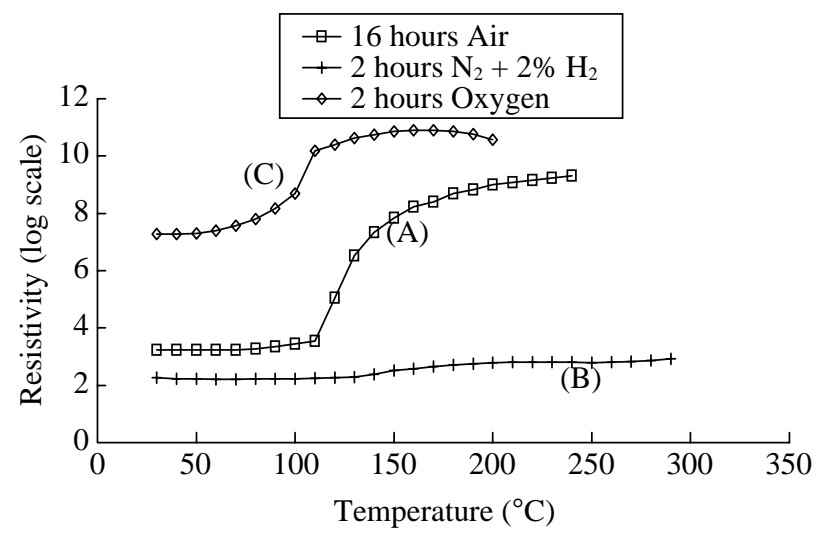

Fig. 9. PTCR characters of composition B annealed sequentially in (1) air for 18 hours; (2) reduced atmosphere $\left(\mathrm{N}_{2}+2 \% \mathrm{H}_{2}\right)$ for 2 hours; (3) oxygen for 2 hours.

as curve $\mathrm{C}$, showing the PTCR phenomena was strongly influenced by the oxygen absorption. Annealing in a reduced atmosphere reduces the resistivity of PTCR ceramics, and also diminishes the PTCR effect of PTCR ceramics. When the sample was re-annealed in an oxygen atmosphere, it became an insulator ceramic with small PTCR phenomena (curve C), showing that annealing in reduced atmosphere improves the conductivity of ceramics without contributing to PTCR effects.

\section{Complex plane analysis}

The equivalent circuit of PTCR ceramic can be expressed as in Figure 10. Since the surfaces of the ceramics were metalized with ohmic contacts and the grains were conductive, the capacitor existed on the surface of ceramic and in the grains can be disregarded. The equivalent circuit of Figure 10 can thus be simplified as in Figure 11. The complex-plane-Impedance analysis [13] method was applied to identify the grain resistance and the grain boundary resistance. An HP4192A impedance analyser was employed to measure the impedance variation corresponding to the frequency changes from DC to 13MHZ. The impedance of Figure 11 is expressed as

$$
Z=R_{b}+\frac{R_{g b}}{1+j \omega R_{g b} C_{g b}}
$$

where $R_{b}$ denotes the effective grain resistance, $R_{g b}$ denotes the effective grain boundary resistance, and $C_{g b}$ denotes effective grain boundary capacitance. Since the measured impedance depends on the input signal frequency, the impedance is $Z=R_{b}$ in the high frequency region, and $Z=R_{b}+R_{g b}$ in the low frequency region.

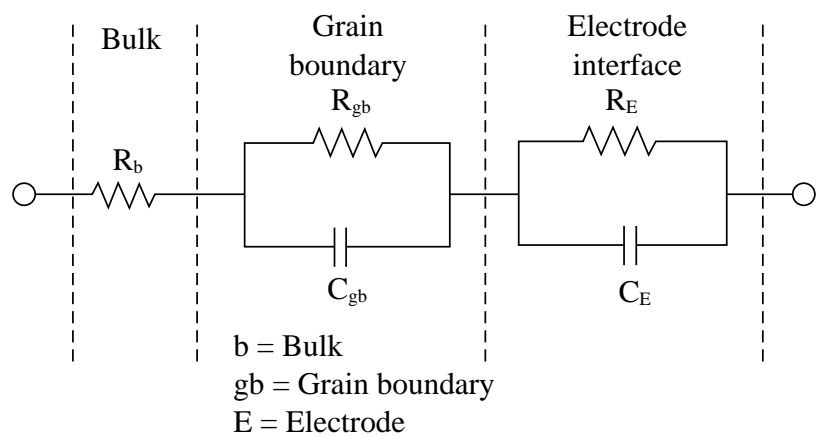

Fig. 10. The equivalent circuit of PTCR ceramic.

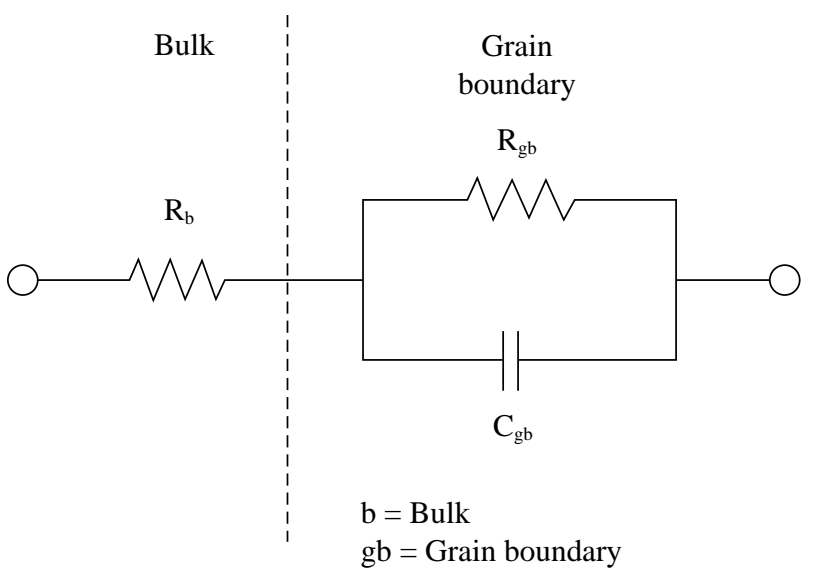

Fig. 11. The simplify equivalent circuit of PTCR ceramic.

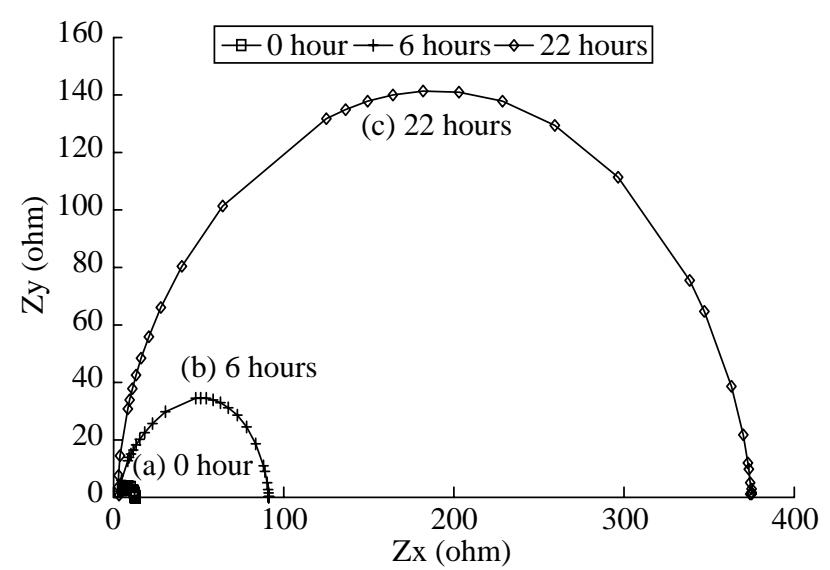

Fig. 12. The impedance plot of composition A for various annealing time.

Figures 12 and 13 show that the grain boundary resistance increases as the annealing time increases. However, the grain resistance remains the same as observed in Figure 14 and Figure 15, showing that the 


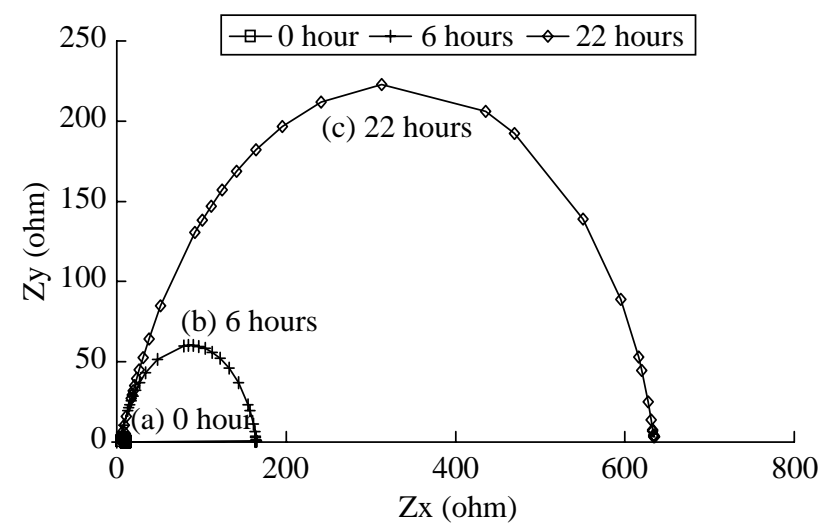

Fig. 13. The impedance plot of composition $B$ for various annealing time.

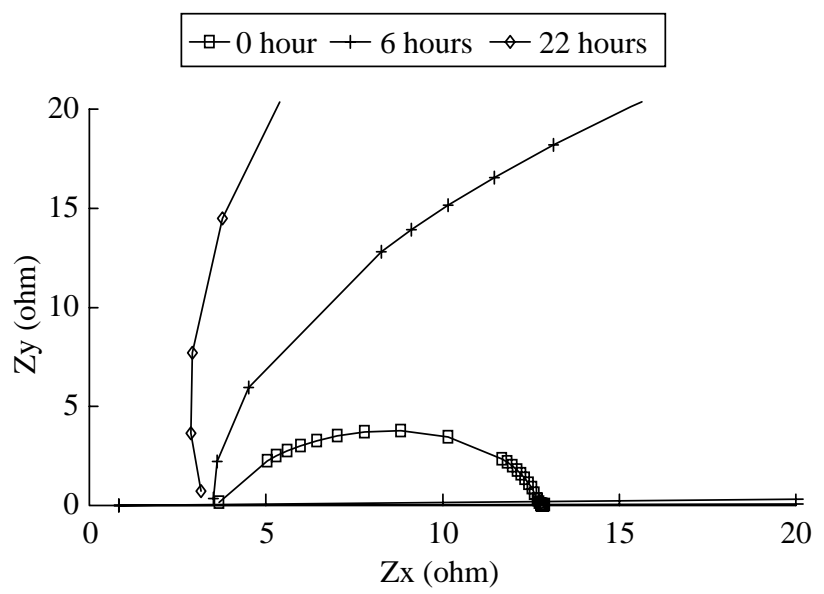

Fig. 14. The expanding impedance plot of Figure 12 by different annealing time at high frequency region.

complex-impedance measurements of the specimens agree with the theoretical deductions of equivalent circuit in Figure 11.

The complex plane measurement results confirm that the grain boundary, unlike the grain resistance, depends strongly on the annealing process. The increase in the grain boundary resistance is due to the formation of a space charge layer caused by the annealing process, showing that the annealing process is an effective way, rather than the cooling process, to control the characteristics of PTCR ceramics and approves with the PTCR mechanism presented in previous discussions.

The grain resistance was found to be about $3.5 \mathrm{ohm}$ for $\left(\mathrm{Ba}_{0.998} \mathrm{Sb}_{0.002}\right) \mathrm{Ti}_{1.005} \mathrm{O}_{3}$ ceramics (Figure 14). The grain boundary resistance increased significantly when $0.1 \mathrm{~mole} \% \mathrm{Mn}^{+4}$ was added to the samples, while the grain resistance increased with the annealing time in the

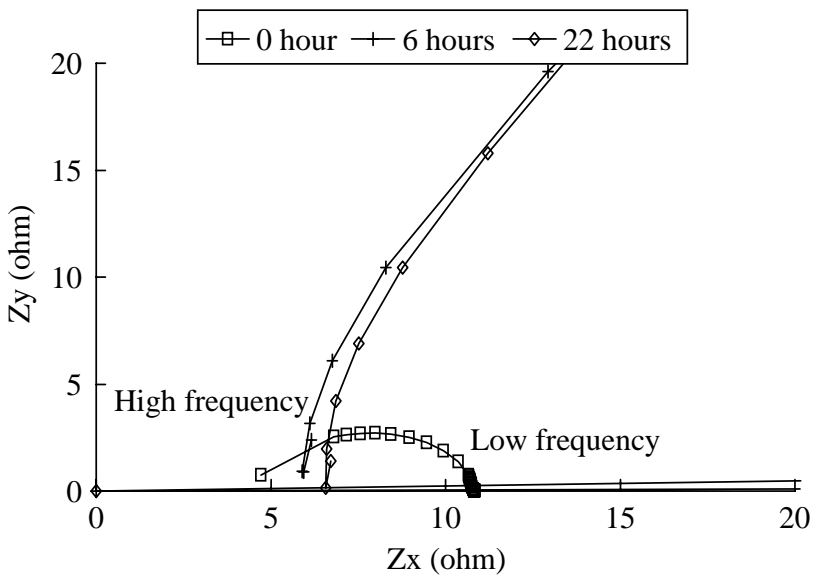

Fig. 15. The expanding impedance plot of Figure 13 by different annealing time at high frequency region.

range of 4.5-6.6 ohms (Figure 15), possibly because most of the $\mathrm{Mn}$ ions were segregated at the grain boundary, increasing both the resistance and barrier height of the grain boundary. However, some Mn ions came into the bulk of the grains (substituting Ti sites) and decreased the electron density, increasing the grain resistance. The grain resistance of the ceramics of composition A, was independent of annealing time, while that of composition B increased as the annealing time increased, because the $\mathrm{Mn}$ was incorporated into the crystals reducing the electron density.

\section{CONCLUSION}

This work examines and discusses the effect of the annealing on the properties of PTCR ceramics. Barium titanate can be made conductive both by donor dopants (valency-controlled) and by anion vacancies (vacancycontrolled). However, PTCR ceramics can be produced only by the valency-control method.

In this investigation, extensive high temperature annealing the valency-controlled ceramics in an oxygen atmosphere produces the formation of barium vacancies that compensate the electron donors. annealing at $1200^{\circ} \mathrm{C}$ was found to control the characteristics of PTCR ceramics well. The annealing process results in the development of the potential barrier by increasing the acceptor state density (Barium vacancies) and enhancing the PTCR effects.

The effects of reduction/re-oxidation on samples annealed in air at $1200^{\circ} \mathrm{C}$ for long period clearly show the presence of an insulating layer, validating the model of Daniels and his co-workers. The dramatic decrease in $R_{\min }$ and the disappearance of the PTCR effect observed in the reduced specimen was explained by ex- 
tending the above model to include the formation of oxygen vacancies, which coexisted with the $\mathrm{Ba}$ vacancies. This experiment confirms that oxygen is a significantly influences on the PTCR effect.

The complex-plane-impedance method was used to verify the influence of annealing condition (temperature, time and atmosphere) on the PTCR devices, finding that PTCR mechanism came from the grain boundaries rather than the bulk phenomenon.

The processing technology and theoretical mechanism of the annealing effect on the PTCR ceramics were designed and discussed in detail herein. Factors which are essential in controlling the PTCR ceramics were studied, showing that the design of the PTCR devices is practical.

\section{ACKNOWLEDGMENT}

The authors would like to thank the National Science Council of the Republic of China, Taiwan for financially supporting this research under Contract No. NSC95-2221-E-272-005.

\section{REFERENCES}

1. Al-Allak, H.M., Russell, G.J., and Woods, J., "The Effect of Annealing on The Characteristics of Semiconducting $\mathrm{BaTiO}_{3}$ Positive Temperature Coefficient of Resistance Devices," Journal of Physics D: Applied Physics, Vol. 20, pp. 1645-1651 (1987).

2. Ashida, T. and Toyada, H., "The Effect of Additives and of Ambient Atmosphere During Heating on The Electrical Resistivity of Semiconducting $\mathrm{BaTiO}_{3}$," Japanese Journal of Applied Physics, Vol. 5, No. 4, pp. 269-74 (1966).

3. Bigger, J.V. and Gardopee, G.J., "Hydrogen Reduction of $\mathrm{BaTiO}_{3}$ Ceramics," Ceramic Bulletin, Vol. 53, No. 12, pp. 53-56 (1974).

4. Brzozowski, E. and Castro, M.S., "Conduction Mechanism of Barium Titanate Ceramics," Ceramic International, Vol. 26, pp. 265-269 (2000).
5. Burn, I., "Mn-Doped Polycrystaiiine $\mathrm{BaTiO}_{3}$," Journal of Materials Science, Vol. 14, pp. 2453-58 (1979).

6. Chatterjee, S. and Maiti, H.S., "A Novel Method of Doping PTC Thermister Sensor Elements During Sintering Through Diffusion by Vapor Phase," Materiala Chemistry and Physics, Vol. 67, pp. 294-297 (2001).

7. Daniels, J., Hardtl, K.H., Hennings, D., and Wernicke, R., "Defect Chemistry and Electrical Conductivity of Doped Barium Titanate Ceramics," Philips Research Reports, Vol. 31, pp. 487-559 (1976).

8. Daniels, J., Hardtl, K.H., and Wenicke, R., "The PTC Effect of Barium Titanate," Philips Technical Review, Vol. 38, No. 3, pp. 73-82 (1978/79).

9. Daniels, J. and Wernicke, R., Philips Res. Rep., Vol. 31, pp. 544-559 (1976).

10. Heywang, W., "Semiconducting Barium-Titanate," Journal of Material Science, Vol. 6, pp. 1214-1224 (1971).

11. Ihrig, H., "PTC Effect in $\mathrm{BaTiO}_{3}$ as a Function of Doping With 3d Elements," Journal of American Ceramic Society, Vol. 64, pp. 617-20 (1981).

12. Kahn, M., "Effect of Heat-Treatment on the PTCR Anomaly in Semiconducting Barium Titanate," American Ceramic Society Bulletin, Vol. 50, pp. 676-680 (1970).

13. Levinson, L.M., "Equilibrium Barrier in PTC Thermistors, Grain Boundary Phenomena in Electronic Ceramics," Symposium of the 82nd Annual Meeting of the American Ceramic Society, Chicago, IL (1980).

14. Qi, J., Gui, Z., Wu, Y., and Li, L., "Enhance of PTCR Effect of Semiconducting $\mathrm{Ba}_{1-\mathrm{x}} \mathrm{Sr}_{\mathrm{x}} \mathrm{TiO}_{3}$ by $\mathrm{Sb}_{2} \mathrm{O}_{3}$ Vapor, "Sensors Actuator A Physical, Vol. 93, pp. 84-85 (2001).

15. Saburi, O., "Properties of Semiconducting $\mathrm{BaTiO}_{3}$," Journal of the Physical Society of Japan, Vol. 14, No. 9, pp. 1159-1174 (1959).

16. Tien, T.Y. and Carlson, W.G., "Influence of Oxygen Partial Pressure on Properties of Semiconducting Barium Titanate," Journal of American Ceramic Society, Vol. 46, No. 6, pp. 297-298 (1963).

17. Veijola, T., "Large-Signal Simulation Model for PTC Thermistor," Proceedings of ECCTD'99, Stresa, Italy, Vol. 2, pp. 687-690 (1999). 